Article

\title{
Experimental Investigation on Emissions Characteristics from Urban Bus Fueled with Diesel, Biodiesel and an Oxygenated Additive from Residual Glycerin from Biodiesel Production
}

\author{
Carmen C. Barrios ${ }^{1, *}$, Paloma Álvarez-Mateos ${ }^{2}\left[\right.$, Ana Urueña ${ }^{3}$, David Díez ${ }^{3}(\mathbb{C}$ \\ and Juan Francisco García-Martín ${ }^{2}$ (D) \\ 1 Research Centre for Energy, Environmental Department, Environment and Technology (CIEMAT), \\ Avda. Complutense, 40, 28040 Madrid, Spain \\ 2 Departamento de Ingeniería Química, Facultad de Química, Universidad de Sevilla, C/Profesor García \\ González, s/n, 41012 Sevilla, Spain; palvarez@us.es (P.Á.-M.); jfgarmar@us.es (J.F.G.-M.) \\ 3 CARTIF Centro Tecnológico, Parque Tecnológico de Boecillo, 205, 47151 Valladolid, Spain; \\ anauru@cartif.es (A.U.); davdie@cartif.es (D.D.) \\ * Correspondence: carmen.barrios@ciemat.es
}

Citation: Barrios, C.C.; ÁlvarezMateos, P.; Urueña, A.; Díez, D.; García-Martín, J.F. Experimental Investigation on Emissions Characteristics from Urban Bus Fueled with Diesel, Biodiesel and an Oxygenated Additive from Residual Glycerin from Biodiesel Production. Processes 2021, 9, 987. https:/ / doi.org/10.3390/pr9060987

Academic Editors: Alessandro d'Adamo and Albert Ratner

Received: 6 April 2021

Accepted: 29 May 2021

Published: 3 June 2021

Publisher's Note: MDPI stays neutral with regard to jurisdictional claims in published maps and institutional affiliations.

Copyright: (c) 2021 by the authors. Licensee MDPI, Basel, Switzerland. This article is an open access article distributed under the terms and conditions of the Creative Commons Attribution (CC BY) license (https:// creativecommons.org/licenses/by/ $4.0 /)$

\begin{abstract}
The aim of the study was to assess the influence of the addition of an oxygenated additive (a mixture of mono-, di- and triacetylglycerol obtained from residual glycerin within the biodiesel production scheme) on the specific fuel consumption and exhaust emissions of a EURO 3 diesel bus during its daily route through the city. To do this, the urban bus was fuelled with five fuel blends of diesel (D), biodiesel (B), additive (A) and heptanol as co-surfactant (H). A portable emissions measurement system was used to measure the exhaust gases while an engine exhaust particle system with a dilution system, both installed on the urban bus, was used for nanoparticles measurement in actual operating conditions through the city of Seville. Results showed that B95A5 (95\%v/v biodiesel, $5 \% \mathrm{v} / \mathrm{v}$ additive) and B90A10 were the blends that most increased $\mathrm{NO}_{\mathrm{x}}$ emissions (by $24.12 \%$ and $9.85 \%$, respectively) compared to D100. On the other hand, B47.5D47.5A2.5H2.5 was the blend that most reduced total particle number (by $31.6 \%$ ) and $\mathrm{NO}_{x}$ emissions (by $12 \%$ ). All in all, the oxygenated additive can be efficiently blended with biodiesel to reduce particle emissions from engines without diesel particle filter, such as those in urban buses in many European cities.
\end{abstract}

Keywords: exhaust emissions; glycerin; oxygenated additives; on-board measurement; particle emissions

\section{Introduction}

The United Kingdom and the European Union plan to accelerate a greener transport future. In this context, diesel fuel takes the brunt of the climate change action plans since it is regarded (maybe wrongly) as the fuel contributing the most to greenhouse gases. Thus, conventional gasoline and diesel vehicles are set to be banned from sale in 2030 in the United Kingdom and in 2040 in many European countries. While current urban regulations restrict the access of older diesel vehicles to city centres in many European cities such as Milan, London, Paris, Stuttgart and Brussels, cars with modern diesel engines, mainly Euro 5 and Euro 6 models, will continue to be allowed to drive in most cities across Europe.

At present, diesel buses still represent the largest part of the urban bus fleet in European cities. Some of these cities keep old buses that meet Euro 3 regulations within their urban transport fleet. Until relatively recently, the use of diesel engines in urban transport was widespread due to their high thermal efficiency, low fuel consumption and reliability, and only recently the use of natural gas has been introduced in order to try to reduce the impact on the city environment. Notwithstanding, fleets equipped with old engines running on conventional diesel remain relevant. Such is the case of cities such as Lisbon in Portugal where $89 \%$ of the urban diesel buses for public transport have Euro 3 or 
earlier regulations [1], or Athens in Greece where $85 \%$ of the fleet of urban diesel buses for public transport also have E3 or previous regulations [2]. Even in countries known for their high environmental awareness, such as France, roughly $25 \%$ of their global bus fleet maintain these old regulations [3]. In the case of Seville (Spain) around $40 \%$ of the urban bus fleet for public transport circulates across the city with this Euro 3 regulation, while using conventional diesel as fuel. This represents a significant emission of polluting gases such as $\mathrm{NO}_{\mathrm{x}}, \mathrm{CO}$ and total hydrocarbons (THC) and a relevant amount of particles, which is the main problem of this engine technology [4].

Emissions of pollutants such as $\mathrm{NO}_{\mathrm{x}}$ (an irritant gas) and particles affect the quality of the air that citizens breathe, especially or those who live in urban areas where the concentration of vehicles and public transport is very high. The exhaust gas from the internal combustion engines that propel passenger transport buses in urban areas of highly populated cities such as Seville (Spain) is especially harmful to the health of the people who travel its streets, especially of people waiting at bus stops or passing nearby, due to the proximity to the source of emission.

Diesel engines represent a very important source of emission of nanoparticles mainly composed of hydrocarbons and soot aggregates [5]. According to these authors, nanometric particles $(<50 \mathrm{~nm})$, once inhaled by people, can reach interstitial sites in the respiratory tract or penetrate so deeply as to cross the alveolar epithelial barrier and enter the bloodstream and lymphatic system to be transported to extrapulmonary organs. The increase in respiratory problems for many people in the most populated areas can be attributed to the long distance travelled within the respiratory system by these particles [6].

On the other hand, $\mathrm{NO}_{\mathrm{x}}$ emissions can also cause damage to health, mainly asthma, inflammation of the respiratory system and damage to lung function. Its inhalation is associated with diseases both irreversible (e.g., emphysema, immunopathology, cardiovascular defects, cancer) and reversible (e.g., asthma, nausea, skin irritation, shortness of breath, cough, wheezing) [7]. This underlines the importance of the search for fuels and additives of biological or residual origin to reduce these emissions and, therefore, their impact on the human health.

The use of biodiesel has long been a fuel alternative for these vehicles aiming at reducing the environmental impact of their emissions. However, problems related to the quality of available biodiesel, the use of raw materials also used for food, and supply and distribution issues have significantly slowed its implementation in Seville. On the other hand, the excess of residual glycerin generated in the biodiesel production (through the oil transesterification process) also causes problems for biodiesel producers. As a result, researchers have paid attention not only to the improvement of the biodiesel production process and the search for new raw materials, but also to the additional use of residual glycerin with the aim of reducing the impact of pollutants from these vehicles, in the short term, on the environment [8-10]. One of these alternative raw materials for biodiesel production, which is currently already being used, is waste cooking oil. In the case of the whole area of Andalusia in which the city of Seville is included, the amount of oil that is discarded, especially from the HORECA (hotel, restaurant and catering) sector, reaches 58,000 t/year [11]. The discharge of waste cooking oils is responsible for many environmental negative effects (sludge production, eutrophication and proliferation of bacteria and pathogenic microorganisms, among others) [12]. This proves the importance of preventing waste cooking oils from ending up as waste in drains and sewers and promoting beneficial uses for the local community, which could be replicated in other cities with the same problems.

Oxygenated additives are chemical substances that, added in small quantities to diesel or biodiesel, improve acceleration, engine performance and fuel consumption while reducing greenhouse gas emissions [13,14]. The products obtained from the esterification of glycerol, namely monoacetylglycerol (MAG), diacetylglycerol (DAG) and triacetylglycerol (TAG), are suitable as oxygenated additives for gasoline, biodiesel and diesel $[10,15]$. Therefore, the glycerol contained in the residual glycerin from the biodiesel production 
could be used for the production of oxygenated additives in order to improve engine combustion performance and reduce exhaust emission of urban bus fleets with diesel engines meeting older regulations.

In this work, gases and nanoparticles were measured in real time with equipment installed inside an urban bus in use, belonging to the urban transport company of Seville (TUSSAM). The measurements were made at $50 \mathrm{~cm}$ from the exhaust pipe outlet and with five fuel blends. These fuel blends contained commercial diesel (D), biodiesel from waste cooking oil (B), oxygenated additive (mixture of MAG, DAG and TAG) from the processing of residual glycerin $(\mathrm{A})$ and heptanol as co-surfactant $(\mathrm{H})$ in different volume percentages (indicated by the number in the name): D100, B30D70, B90A10, B95A5, B47.5D47.5A2.5H2.5. The equipment used in this research was a portable emissions measurement system (PEMS) for the measurement of exhaust gases and an engine exhaust particle system (EEPS) with a dilution system for the measurement of nanoparticles emitted by a 12-m-long Iveco Cityclass diesel bus complying with EURO 3 regulations under actual operating conditions. To be specific, three different, currently active urban bus routes were assayed resulting in $708 \mathrm{~km}$ traveled during which exhaust emissions were measured. While it is important to categorize pollution effects on people at bus stops and surroundings, the assessment of broader, citywide pollution resulting from emissions during the whole driving time is of major importance. Hence, the primary goal of this research was to perform an experimental characterization of emissions from engine combustion for the aforementioned fuels in the context of city air quality, with regard to the issues of bus transportation (frequent stops in crowded areas, etc.).

\section{Materials and Methods}

\subsection{Fuels, Raw Materials and Reagents}

Commercial diesel was supplied by Repsol S.A. (Madrid, Spain). Biodiesel from waste cooking oil and residual glycerin were obtained in a pilot plant (Figure 1). The pilot plant is composed of an innovative oscillatory flow reactor with cavitation; followed by a decanter, where the crude glycerin is separated from the biodiesel; two distillers, one for the biodiesel and the other for the crude glycerin to separate the methanol in order to reuse it; condensers to liquefy the evaporated methanol and basket filters to purify the biodiesel and thus comply with the UNE 14214 standard. The oscillatory flow reactor was built from the results obtained in a previous work [9]. The chemical reagents used were heptanol $(\mathrm{H})$ ( $98 \%$, Sigma-Aldrich Co., St. Louis, MO, USA) and acetic acid (AA) $(99 \%$, Cofarcas, Burgos, Spain), while dry Amberlyst-15 (DuPont de Nemours, Inc., Wilmington, DE, USA) was used as catalyst.

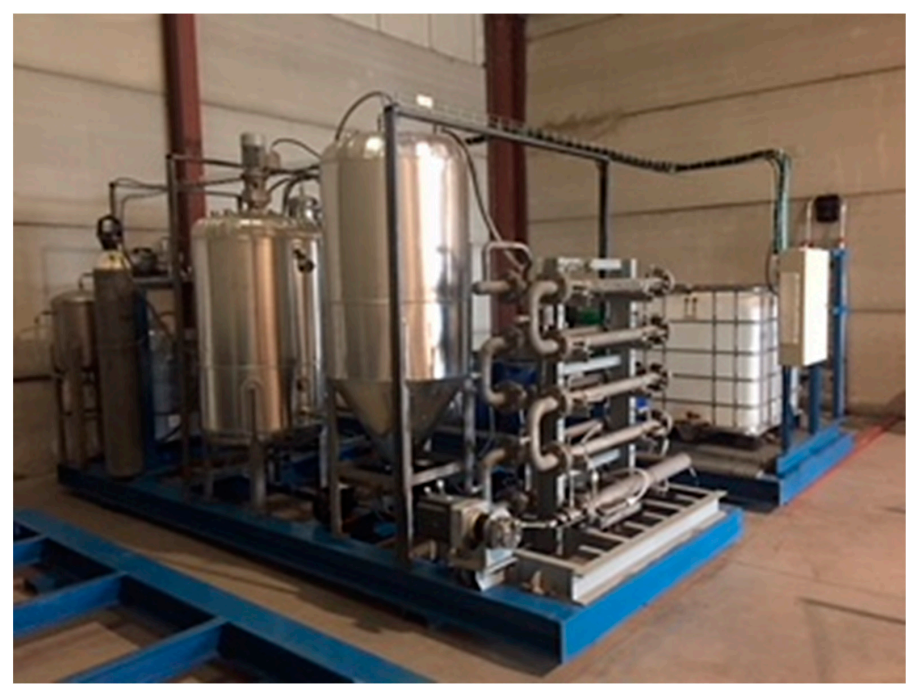

Figure 1. Pilot plant for the production of the biodiesel and glycerin used in this research. 
Production of the Oxygenated Additive

The methodology followed for the purification of residual glycerin and subsequent production of the oxygenated additive (a mixture of mono-, di- and triacetylglycerol) is described elsewhere [10]. The operating conditions selected for the production of the oxygenated additive were $115^{\circ} \mathrm{C}, 9: 1 \mathrm{AA} /$ glycerin molar ratio, $200 \mathrm{rpm}$ stirring, $180 \mathrm{~min}$ reaction time and 0.2 Amberlyst- 15 to glycerin mass ratio [10].

The equipment used to produce the oxygenated additive was a $50 \mathrm{dm}^{3}$ stirred batch reactor, equipped with a heating system by means of thermal oil. Once the reaction was completed, the product was filtered to remove the catalyst and evaporated in a rotary evaporator in order to separate the excess AA from the oxygenated additive.

The composition (\%wt.) of the oxygenated additive was 8.24 $\pm 2.89 \mathrm{MAG}, 67.66 \pm 0.71$ DAG and $24.10 \pm 3.49$ TAG.

\subsection{Analytical Methods}

Density at $15^{\circ} \mathrm{C}$ and boiling temperature were determined following UNE-EN ISO 3675 and UNE-EN ISO 12185 standards, and the UNE-EN 14213 standard, respectively. The lower heating value was calculated following the ASTM D240-09 standard using a Parr 1341 plain jacket calorimeter bomb (Parr Instrument Company, Moline, IL, USA) while viscosity at $25{ }^{\circ} \mathrm{C}$ was measured by a HAAKE modular advanced rheometer system (Thermo Electron Corporation, Waltham, MA, USA). The flash point was obtained using a FG-K16909-KW flash point tester (Parker Hannifin Corporation, Cleveland, OH, USA).

Elemental analysis was carried out in a CHNS-932 elemental analyzer (LECO, St. Joseph, MI, USA). From this composition, the latent heat of vaporization was calculated.

The cetane number of biodiesel was obtained from its fatty acid methyl esters (FAME) profile as described elsewhere [16]. FAME percentages were calculated following the UNE-EN 14103:2011 and UNE-EN ISO 12966-1:2015 standards. The cetane number of commercial diesel was provided by the manufacturer.

\subsection{Biofuels Formulation}

The biofuel formulation was made always using the same diesel (D), biodiesel (B), oxygenated additive (A) and heptanol $(\mathrm{H})$. Their properties, measured as described in the previous section, are illustrated in Table 1 . The oxygenated additive was added to the diesel or biodiesel fuel used as base; the co-surfactant (heptanol) was added only to the blend with diesel because of the low miscibility of the oxygenated additive in diesel. The fuel blends formulated and used throughout this study were B30D70, B90A10, B95A5 and B47.5D47.5A2.5H2.5, which were stable for more than six months. Commercial diesel (D100) was used as the reference fuel.

Table 1. Main fuel properties of commercial diesel, biodiesel from waste cooking oil, oxygenated additive and heptanol.

\begin{tabular}{lcccc}
\hline \multicolumn{1}{c}{ Property } & Commercial Diesel & Biodiesel & Additive & Heptanol \\
\hline Formula & $\mathrm{C}_{12} \mathrm{H}_{22.44}$ & $\mathrm{C}_{19} \mathrm{H}_{36} \mathrm{O}_{2}$ & $\mathrm{C}_{9} \mathrm{H}_{14} \mathrm{O}_{6}$ & $\mathrm{C}_{7} \mathrm{H}_{16} \mathrm{O}$ \\
Cetane number & 51.3 & 62.5 & - & - \\
Viscosity at $25^{\circ} \mathrm{C}(\mathrm{mPa} \cdot \mathrm{s})$ & 2.9 & 4.1 & 23.0 & 7.4 \\
Density at $15^{\circ} \mathrm{C}\left(\mathrm{g} / \mathrm{dm}^{3}\right)$ & 840 & 882 & 1155 & 820 \\
Boiling point $\left({ }^{\circ} \mathrm{C}\right)$ & - & 345 & 259 & 176 \\
Stoichiometric fuel/air ratio $(\mathrm{m} / \mathrm{m})$ & $1 / 14.5$ & $1 / 12.5$ & $1 / 6.0$ & $1 / 12.4$ \\
Latent heat of vaporization $(\mathrm{kJ} / \mathrm{kg})$ & 270 & 22,888 & 18,312 & 7809 \\
Lower heating value $(\mathrm{MJ} / \mathrm{kg})$ & 43.9 & 38.9 & 17.0 & 40.0 \\
Flash point $\left({ }^{\circ} \mathrm{C}\right)$ & 40.0 & 90.5 & 138.0 & 78.0 \\
$\mathrm{C}(\% w t)$. & 86.4 & 78.1 & 49.5 & 72.4 \\
$\mathrm{O}(\% w t)$. & 0.0 & 9.9 & 44.4 & 13.8 \\
$\mathrm{H}(\% w t)$. & 13.6 & 11.9 & 6.4 & 13.8 \\
\hline
\end{tabular}

Once the oxygenated additive was obtained, new fuels were formulated by blending diesel, biodiesel and the additive, creating time-stable microemulsions of these components 
in order to improve combustion properties in engine. Biodiesel-oxygenated additive blends were miscible, but oxygenated additive and diesel were found to be immiscible due to their different viscosity and polarity. In order to blend the oxygenated additive with diesel, it was necessary to form a microemulsion using a co-surfactant [17-20]. In this sense, microemulsions with heptanol are those that present characteristics closer to diesel [21], so it was selected as a co-surfactant.

Therefore, the blends were formulated by the following components: the additive, the alcohol, and biodiesel and diesel as a non-polar compound. They were three-phase mixtures. The continuous phase was biodiesel/diesel, the dispersed phase was the oxygenated additive and heptanol acted as co-surfactant [21-23].

For the development of the tests in urban buses and due to the age of the engines, a relatively low concentration of additive was assayed to prevent potential unexpected problems.

\subsection{Urban Bus}

The experimental study was carried out with an in-use diesel urban bus, manufactured by the company IVECO meeting Euro 3 emission standard. This is one of the most commonly used models in urban fleet in Seville. The mileage of the bus before the trials was $593,815 \mathrm{~km}$. The bus is equipped with a diesel oxidation catalyst acting as an exhaust gas after-treatment system. The technical specifications of the bus are illustrated in Table 2.

Table 2. Main specifications of the urban bus used in this research.

\begin{tabular}{lc}
\hline \multicolumn{1}{c}{ Parameter } & Value \\
\hline Bus type & IVECO CURSOR 8 F28 E0682C \\
Model year & 2003 \\
Emission standard & Euro 3 \\
Configuration & In-line 6 cylinders \\
Air intake & Turbocharged with aftercooler \\
Fuel injection & Direct injection (Bosch type $)$ \\
Displacement & $7790 \mathrm{~cm}^{3}$ \\
Diameter $\times$ stroke & $115 \times 125 \mathrm{~mm}$ \\
Compression ratio & $16 \pm 0.8: 1$ \\
Max torque & $1100 \mathrm{Nm} \cong 1000 \div 1900 \mathrm{rpm}$ \\
Max power & $213 \mathrm{~kW}(290 \mathrm{CV}) \cong 2400 \mathrm{rpm}$ \\
Exhaust gas recirculation & Yes \\
Diesel particle filter & $\mathrm{No}$ \\
Length & $12,000 \mathrm{~mm}$ \\
\hline
\end{tabular}

\subsection{Onboard Test System}

The test system used throughout this research was composed of the previously described urban bus, a particulate test unit, a gas test unit, a dilution system and a power supply unit (Figure 2). Exhaust gas and particle size distribution were measured using an engine exhaust particle sizer (EEPS) spectrometer model 3090 (TSI Incorporated, Shoreview, MN, USA) [24] and a rotating disc raw gas diluter Testo MD19-2E (Matter Engineering, Saint-Germain-de-la-Coudre, France). The control of thermodynamic properties of the sample prevents particle nucleation from the volatile compounds present in the exhaust gas. The dilution system and particle sampling has been widely demonstrated and illustrated by other authors [25-27] and in previous publications of the authors [28,29]. An OBS 2200 (HORIBA Inc., Kyoto, Japan) portable emissions measurement system (PEMS) was used to measure the pollutants concentrations $\left(\mathrm{CO}, \mathrm{CO}_{2}, \mathrm{THC}\right.$ and $\left.\mathrm{NO}_{\mathrm{x}}\right)$ in the exhaust gas. This equipment also includes a flowmeter, a hygrometer, and a GPS for continuously recording the speed and position of the bus. Additionally, various operating parameters of the bus on the road, such as speed, flow of exhaust gas, temperature of the exhaust gas and fuel temperature, were continuously recorded at $1 \mathrm{~Hz}$. 


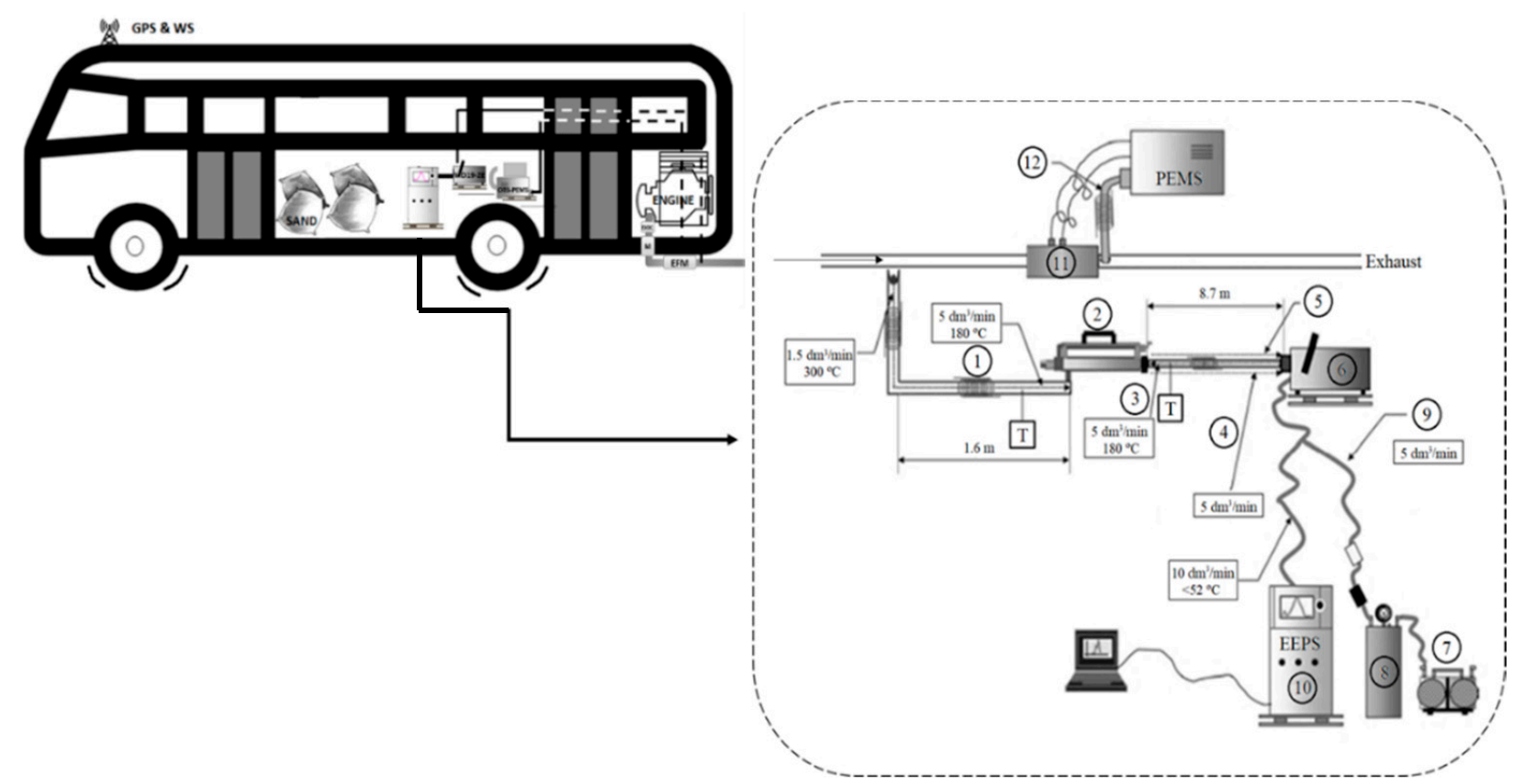

Figure 2. Test system. 1: hot line; 2: sample; 3: hot air dilution; 4: diluted sample; 5: non-diluted sample; 6: dilution control; 7: air compressor; 8: air tank; 9: second air dilution; 10: second sample dilution; 11: flowmeter; 12: hot line.

The measurement of exhaust emissions was performed following the protocols of Horiba Inc. (Tokyo, Japan) for the measurement with its OBS 2200 portable emissions measurement system, i.e., gas sampling was carried out $50 \mathrm{~cm}$ from the exhaust pipe outlet to avoid errors derived from the measurement of the emissions at the end, and not inside- the tailpipe, which are associated with the uncontrolled dilution of the emissions by the ambient air in the rear area of the vehicle. As a consequence of the aerodynamicity due to the shape of the vehicle, turbulence is generated in the airflow resulting in swirls of random shapes and sizes. This is especially important in the case of particles because they can change their morphology due to environmental conditions that could not be controlled. These protocols have been approved and widely used for this type of test in the actual operating conditions of vehicles. The OBS 2200 portable emission measurement system meets the requirements for linearity, accuracy, noise, and repeatability required by the EPA CFR 1065.602 test procedure [30].

\subsection{Test Design and Routes \\ 2.6.1. Experimental Design}

For the design of the experiments, three urban routes of a EURO 3 diesel bus belonging to the current active fleet of 408 buses of TUSSAM, of which $40.7 \%$ have the same emission characteristics as the studied bus [31], were selected. For the selection of these routes, criteria of average daily intensity (ADI) of vehicles in the city of Seville was used. The routes with the highest frequency by volume of passengers and the number of passengers who usually use them were taken into account, so that the data obtained during experimentation were the most representative of the actual emission of bus traffic in the entire city. In accordance with these premises, three bus routes were selected. Figure 3 shows a schematic diagram of the test routes and Table 3 shows the tests carried out in this study. Each of these routes was traveled three times with each of the blends studied, covering a total of $708 \mathrm{~km}$, which allowed us to sample enough points and decrease experimental error, hence providing an accurate analysis of particulate and gas emission characteristics. 


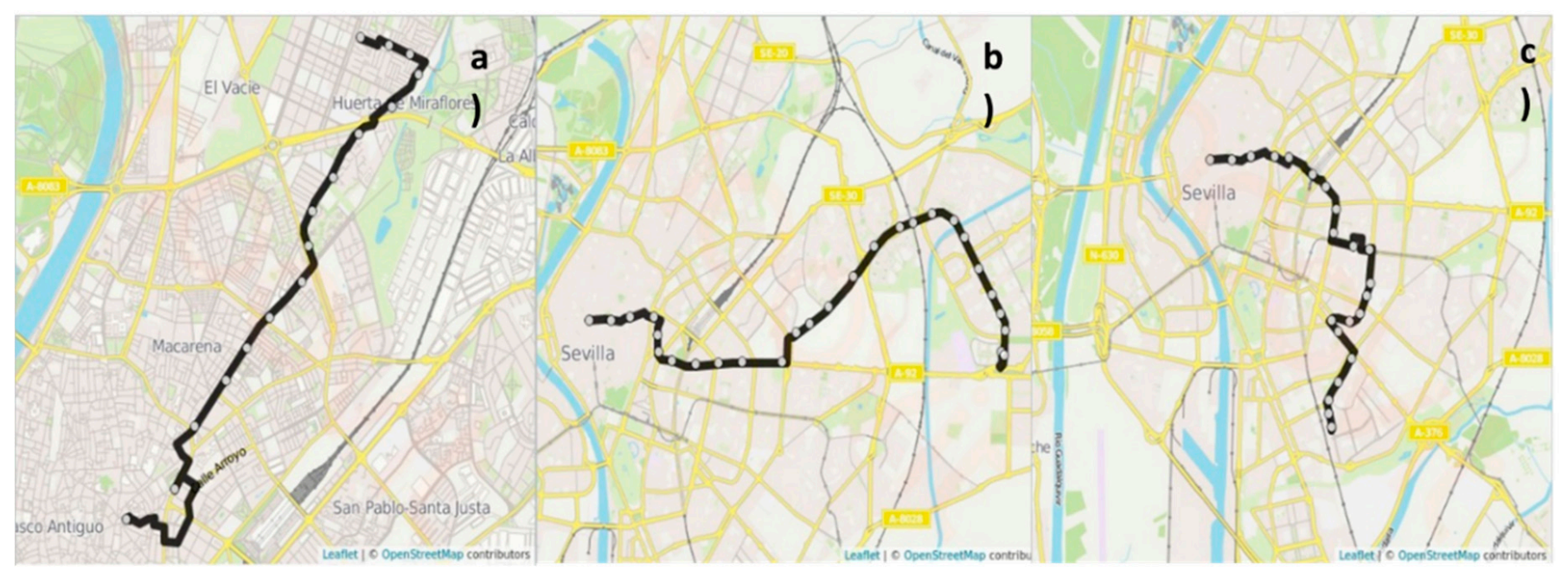

Figure 3. Schematic diagram of the test bus routes. (a) $11.5 \mathrm{~km},(\mathbf{b}) 19.8 \mathrm{~km}$ and (c) $15.6 \mathrm{~km}$.

Table 3. Experimental design.

\begin{tabular}{ccccc}
\hline Test & Route & Fuel & Route Length $\mathbf{( k m )}$ & Average Speed (km/h) \\
\hline 1 & $\mathrm{a}$ & D100 & 11.5 & 11.43 \\
2 & $\mathrm{a}$ & B30D70 & 11.5 & 12.87 \\
3 & $\mathrm{a}$ & B90A10 & 11.5 & 13.73 \\
4 & $\mathrm{a}$ & B95A5 & 11.5 & 13.74 \\
5 & $\mathrm{a}$ & B47.5D47.5A2.5H2.5 & 11.5 & 14.11 \\
6 & $\mathrm{~b}$ & D100 & 19.8 & 13.93 \\
7 & $\mathrm{~b}$ & B30D70 & 19.8 & 15.21 \\
8 & $\mathrm{~b}$ & B90A10 & 19.8 & 16.01 \\
9 & $\mathrm{~b}$ & B95A5 & 19.8 & 20.09 \\
10 & $\mathrm{~b}$ & B47.5D47.5 A2.5H2.5 & 19.8 & 19.37 \\
11 & $\mathrm{c}$ & D100 & 15.6 & 11.17 \\
12 & $\mathrm{c}$ & B30D70 & 15.6 & 11.81 \\
13 & $\mathrm{c}$ & B90A10 & 15.6 & 12.30 \\
14 & $\mathrm{c}$ & B95A5 & 15.6 & 13.77 \\
15 & $\mathrm{c}$ & B47.5D47.5 A2.5H2.5 & 15.6 & 15.97 \\
\hline
\end{tabular}

Route (a) comprised $43.75 \%$ urban section and the rest section was suburban with 16 stops, the total distance of the route being roughly $11.5 \mathrm{~km}$. Route (b) comprised $20.7 \%$ urban section with 29 stops, and the total distance of the route was approximately $19.8 \mathrm{~km}$. Route (c) comprised $23.07 \%$ urban section with 26 stops, and the total distance of the route was roughly $15.6 \mathrm{~km}$. There were 28 traffic lights throughout route (a), 76 throughout route (b) and 57 throughout route (c). The bus idled for $2 \mathrm{~min}$ at each bus stop except for the initial stop of the route, where the bus was idling for between 2 and 5 min to meet the route timetable. Data from each route was recorded at the same period over all working days under similar traffic conditions. The same bus driver was selected for the three routes across Seville, aiming to avoid the bus emissions being affected by different bus drivers' driving styles. There was no passenger transportation during the tests due to security issues, but the weight that would correspond to the average number of occupants of the bus was simulated with sandbags arranged along the bus.

\subsubsection{Sampling Methods and Operating Conditions Sampling Methods}

The EEPS was responsible for sampling particle emissions in real time with a sampling frequency of $1 \mathrm{~Hz}$. The rate of total particle number $(\mathrm{PN})$ emission and the distribution of particle size of 32 measurement levels between 5.6 and $560 \mathrm{~nm}$ were measured directly at the gas exhaust. At the same time, the GPS device recorded the running state of the 
bus in order to relate particle emissions characteristics to bus running conditions. During sampling, the pilot tube flowmeter measured the exhaust flow rate of the bus. Afterwards, the exhaust gas was subjected to two dilutions, the first using the rotating disk diluter for particulate emission with air heated up to $180^{\circ} \mathrm{C}$ and with a dilution factor (DF) of 1:1700. Subsequently, a second dilution $(\mathrm{DF}=1: 2)$ with dry, particle-free air at ambient temperature was performed.

The total dilution ratio was 1:3400, which was chosen to avoid the effects of the condensation of hydrocarbons (HC) and vapor present in the exhaust gas on the measuring of particulate emissions based on the recommendations provided by other authors [25].

\section{Operating Conditions}

Regulated emissions and particle emissions in number and size distribution were measured in transient conditions dictated by traffic on each urban transport line, during the normal operation of the bus. The operating conditions were monitored at $1 \mathrm{~Hz}$. Three tests were performed on each urban transport route and each fuel, in order to ensure repeatability of measurements despite potential outliers. A 5-min cleaning test was carried out before each fuel change to ensure that all fuel lines contained the new fuel to be tested.

The data were recorded under good weather conditions with the air conditioning system switched off. Furthermore, the measurements were performed at the same periods including peak and off-peak hours to minimize the effects of different traffic conditions.

\section{Results and Discussion}

\subsection{Urban Bus Tests}

As explained in the experimental design in Materials and Methods section, three actives routes in Seville city were run in actual operating conditions using an Iveco Cityclass diesel bus that complies with Euro 3 regulations with five fuel blends. Considering that each experimental route was repeated three times, a total of 45 experimental tests were performed, with $708 \mathrm{~km}$ traveled around the city of Seville.

\subsection{Fuel Blends Effects on Fuel Consumption}

The lowest fuel consumption (SFC) was observed for the B47.5D47.5A2.5H2.5 blend (Figure 4) while the highest was the B90A10 blend. This may be due to the influence of the lower heating value (LHV) and the interaction between the thermodynamic properties of the different components of the fuel blends [32]. The LHV of the B47.5D47.5A2.5H2.5 blend $(40.8 \mathrm{MJ} / \mathrm{kg}$ ) is approximately $7 \%$ lower than the LHV of D100 $(43.9 \mathrm{MJ} / \mathrm{kg})$, while the LHV of B90A10 $(37.8 \mathrm{MJ} / \mathrm{kg})$ is roughly $16 \%$ lower than that of D100. The data obtained shows a $20 \%$ decrease in the PN for the B47.5D47.5A2.5H2.5 blend and a $6 \%$ decrease for the $\mathrm{B} 90 \mathrm{~A} 10$ blend, a $10 \%$ increase for the B95A5 blend and a $1 \%$ increase for the blend B30D70 when comparing with D100. This seems to indicate that the use of heptanol as co-surfactant for the blend B47.5D47.5A2.5H2.5 favored the premix phase of the diesel combustion process and the oxygen supply of the additive, which improved combustion efficiency, thus compensating the LHV drop [33]. This fact could represent an advantage for the use of oxygenated additives in diesel engines of vehicles in urban areas, where fuel consumption due to frequent starts and stops and low speeds tends to increase.

\subsection{Fuel Blends Effects on Particulate Emission Characteristics}

To understand the influence of the composition of the blends, Figure 4 shows the specific fuel consumption $(\mathrm{SFC}, \mathrm{g} / \mathrm{km})$, total particle number $(\mathrm{PN}, \# / \mathrm{km})$, geometric mean diameter (GMD, nm), nucleation mode particle number $\left(\# / \mathrm{cm}^{3}\right)$, accumulation mode particle number $\left(\# / \mathrm{cm}^{3}\right)$, and $\mathrm{NO}_{\mathrm{x}}$ emissions $(\mathrm{g} / \mathrm{km})$ of the engine for each diesel/biodiesel/ additive blend. Figure 5 shows the distribution in size and number of particles $\left(\# / \mathrm{cm}^{3}\right)$ for all blends used. 


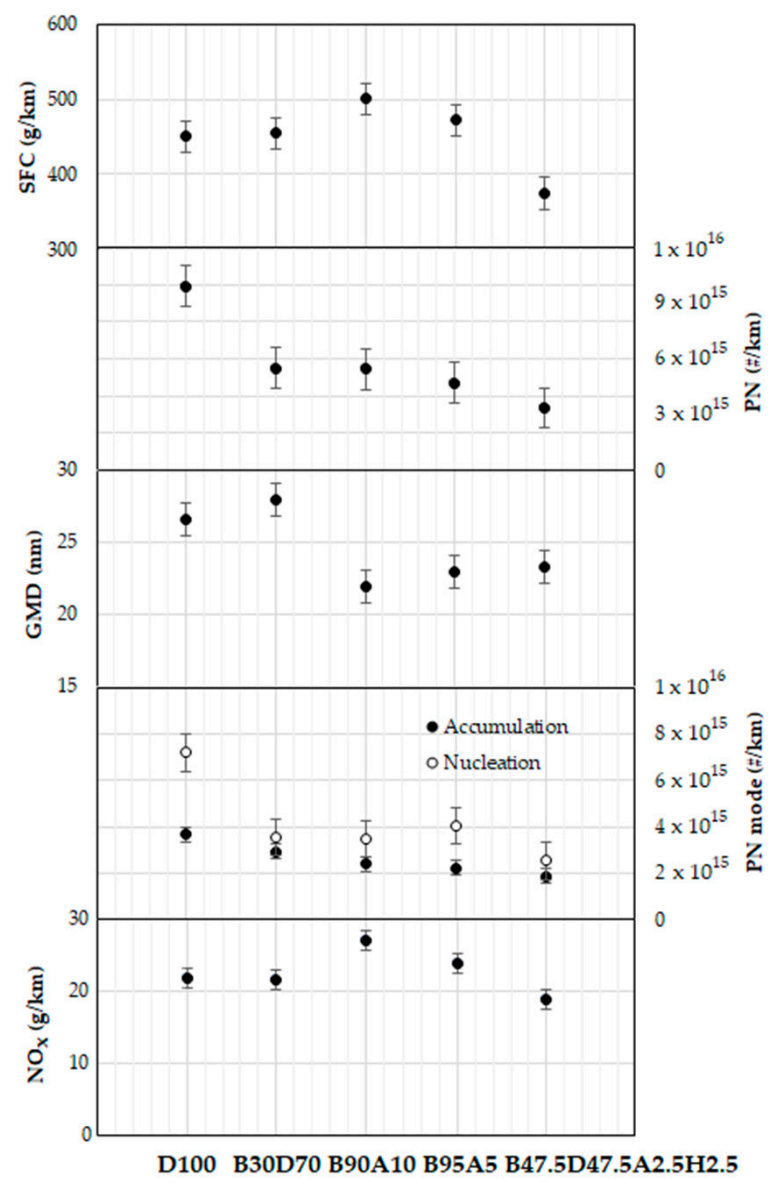

Figure 4. Mean values of emissions of specific fuel consumption (SFC), total particle number (PN), geometric mean diameter (GMD), particle number in accumulation and nucleation mode and $\mathrm{NO}_{\mathrm{x}}$ emissions for D100, B30D70, B90A10, B95A5 and B47.5D47.5A2.5H2.5 in three actives routes across Seville city.

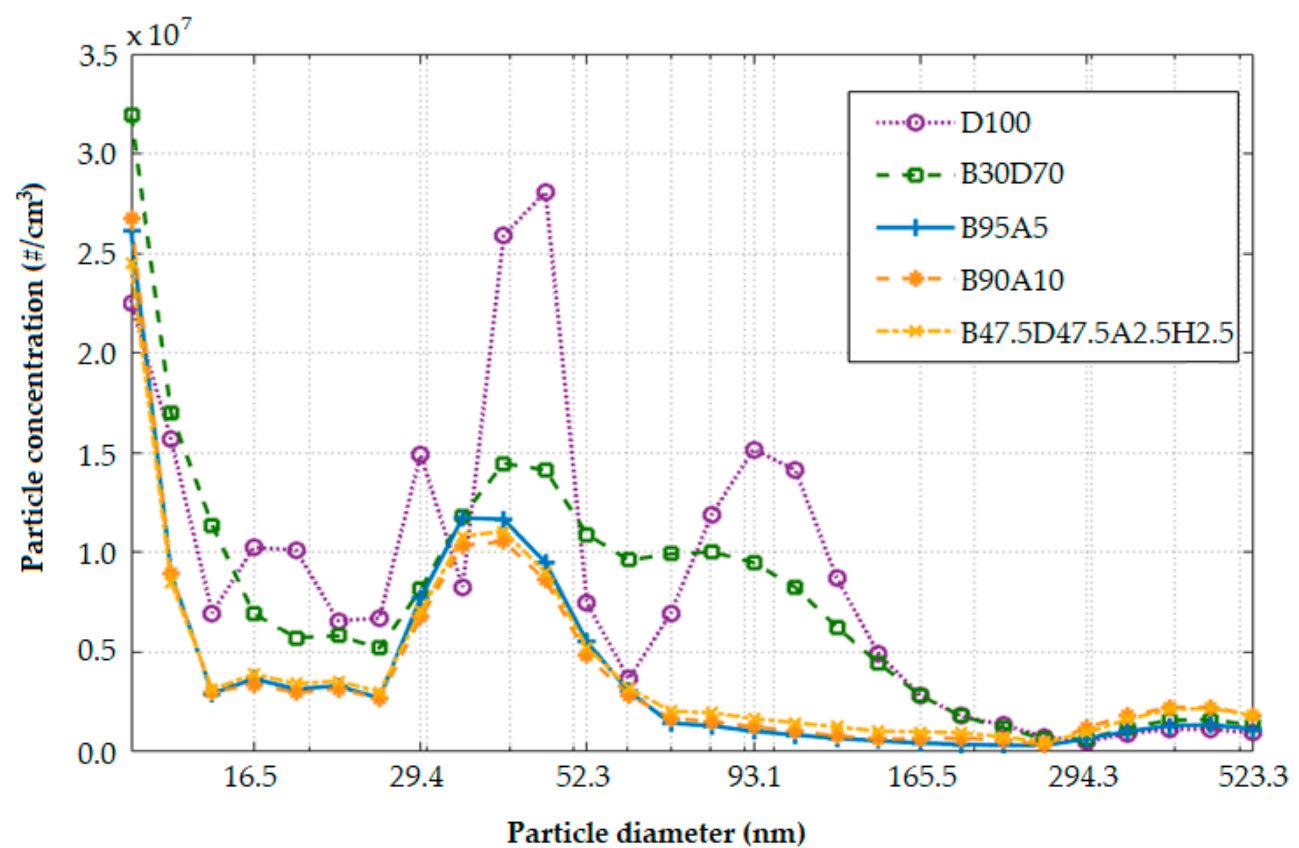

Figure 5. Distribution in size and number of particles for D100, B30D70, B95A5, B90A10 and B47.5D47.5A2.5H2.5 blends, measured in on-board conditions with the bus during three routes across Seville city. 
The total concentration of particles $\left(\# / \mathrm{cm}^{3}\right)$ increased by $40 \%$ when comparing D100 with the B30D70 blend. On the other hand, the total concentration of particles decreased by $28 \%$ for the B90A10 blend, $28.5 \%$ for the B95A 5 blend and $31.6 \%$ for the B47.5D47.5A2.5H2.5 blend when comparing with D100. According to these results, the blend containing the oxygenated additive and heptanol (co-surfactant) was the one that emitted the least number of total particles, which is in agreement with the findings of other authors when assaying etilterbutileter and diglyme as oxygenated additives [34,35]. Therefore, our renewable oxygenated additive has similar or better features than petrol derivatives when using in diesel engines.

The concentration of particles by nucleation (less than $29.4 \mathrm{~nm}$ ) also decreased, as shown in Figure 4, with reduction percentages of around 47\% for the B30D70 blend, 57\% for the B90A10 blend, $55.6 \%$ for the B95A 5 and $60.2 \%$ for the B47.5D47.5A2.5H2.5 blend when comparing with D100. On the other hand, the concentration of particles in accumulation mode ( $>29.4 \mathrm{~nm}$ and $<191.1 \mathrm{~nm}$ ) increased by $6.5 \%$ for the B30D70 blend and decreased by $55.4 \%$ for the B47.5D47.5A2.5H2.5 blend when comparing with D100. This result can be explained by the fact that the oxygen enrichment and the reduced carbon content of biodiesel accelerate the oxidation of primary particles [35]. The reduction of the number of particles in nucleation mode is especially important because a retrofit of the gas aftertreatment system of the buses with diesel particles filters (DPFs) would reduce the emission of particles in accumulation mode, but the emission of particles in nucleation mode would represent a problem, since they cannot be retained in the DPF due to the limitation in retention sizes because of the back pressure that can be generated in the engine exhaust. The reduction of the total number of particles is a very important result when considering emissions from internal combustion engines and air pollution in urban areas. Therefore, it would be very interesting to continue investigating this type of oxygenated additive from a raw material that is obtained as by-product of the transesterification process, which is regarded, in many cases, as a waste material.

\subsection{Fuel Blends Effects on Geometric Mean Diameter (GMD)}

The geometric mean diameter of the emitted particles (particle diameter $>20 \mathrm{~nm}$ ) was significantly influenced by the fuel blend used and the operating conditions of the bus engine. The highest GMD, on average, of all the measured routes, was observed for the B30D70 blend $(\mathrm{GMD}=28 \pm 0.3 \mathrm{~nm}$ ). The GMD observed for the other blends (B90A10, B95A5 and B47.5D47.5A2.5H2.5) ranged between 21.9 and $23.32 \mathrm{~nm}$. The general trend was that, as the percentage of oxygenated additive increases, the GMD decreases, which is in agreement with the findings when other oxygenated additives, such as etilterbutileter and diglyme, were added to commercial diesel [34]. The increase in the percentage of biodiesel and additive causes a decrease in the percentage of carbon and an increase in oxygen, favoring the reduction of elemental carbon nuclei, as shown in Figure 4, and decreasing the accumulation and agglomeration phenomena, hence the GMD. In general, when the particle concentration increases, the coagulation phenomena increases, also increasing the mean particle size [36]. In addition, other authors [37] had concluded that the higher the rate of fuel combustion, the lower average excess oxygen during combustion, which combined with higher pressure and temperature levels in the combustion chamber leads to an increase in the nucleation phenomena of elemental carbon and promoted the growth of existing nuclei (higher GMD). This fact is corroborated by the high emission of $\mathrm{NO}_{\mathrm{x}}$ and the low GMD of the B90A10 blend, as illustrated in Figure 4.

\subsection{Fuel Blends Effects on $\mathrm{NO}_{x}$ Emission}

The emission of nitrogen oxides depends significantly on the type of fuel used and the operating conditions of the vehicle's engine. The dependence of the emission of nitrogen oxides on the operating conditions is in turn influenced by the proportion of oxygen in the mixture and the temperature of the combustion process $[34,36,38]$. The $\mathrm{NO}_{\mathrm{x}}$ thermal emission increased with the oxygenated additive in mixtures with oxygenated additive 
proportion greater than $5 \%$, as in the case of B90A10 and B95A5 blends (Figure 4). The reason is that a lower LHV in the blend forces the electronic engine control to change the amount of fuel injected to maintain power, which increases fuel consumption. In the case of the B47.5D47.5A2.5H2.5 blend, the heptanol present in the mixture absorbs the combustion chamber temperature, decreasing the maximum combustion temperature, delaying ignition and therefore decreasing the probability of $\mathrm{NO}_{\mathrm{x}}$ formation. On average, according to the results obtained, the B95A5 and B90A10 blends emitted $24.12 \%$ and $9.85 \%$, respectively, more $\mathrm{NO}_{\mathrm{x}}$ than conventional diesel (D100). On the contrary, the B47.5D47.5A2.5H2.5 blend emitted $12 \%$ less when compared with D100.

\subsection{Effects of Bus Speed and Fuel Type on $\mathrm{NO}_{x}$ and Particles Emissions}

The emission of the total number of particles and $\mathrm{NO}_{\mathrm{x}}$ is influenced by speed. An increase in the number of combustion cycles per time unit leads to an increase in fuel consumption per time unit and therefore to an increase in the emissions generated during the hydrocarbon combustion process. However, when representing the $\mathrm{NO}_{\mathrm{x}}$ and $\mathrm{PN}$ emissions, respectively, against the bus speed (Figures 6 and 7), a different behaviour between two groups of fuels was observed. To be specific, the fuels without the oxygenated additive (D100 and B30D70) were on one side and the fuels with the oxygenated additive (B95A5, B90A10 and B47.5D47.5A2.5H2.5) were on the other. Thus, the type of fuel had a significant influence on total particulate emissions and $\mathrm{NO}_{\mathrm{x}}$ at very similar speeds (between 13 and $17 \mathrm{~km} / \mathrm{h}$ ). The emission of particles decreased and that of $\mathrm{NO}_{\mathbf{x}}$ increased with the addition of the oxygenated additive, which is in agreement with the data shown on these parameters in Figure 4. The formation of $\mathrm{NO}_{x}$ depends fundamentally on the temperature reached inside the combustion chamber during the combustion process while that of particles mainly on the combustion process and on how complete the oxidation of the hydrocarbon is. This means that the decrease in the total number of particles suggests an improvement in the combustion process due to the supply of oxygen by the additive and the increase in $\mathrm{NO}_{\mathrm{x}}$ emission is indicative of an increase in the temperature within the combustion chamber due to a greater release of heat associated with a more complete combustion. In conclusion, the type of fuel has a greater influence on the emission of $\mathrm{NO}_{\mathrm{x}}$ and total $\mathrm{PN}$ than the variation in speed. This is also confirmed by the analysis of variance $(p \leq 0.05)$, which means that the type of fuel is statistically significant, both for $\mathrm{NO}_{\mathrm{x}}$ and $\mathrm{PN}$.

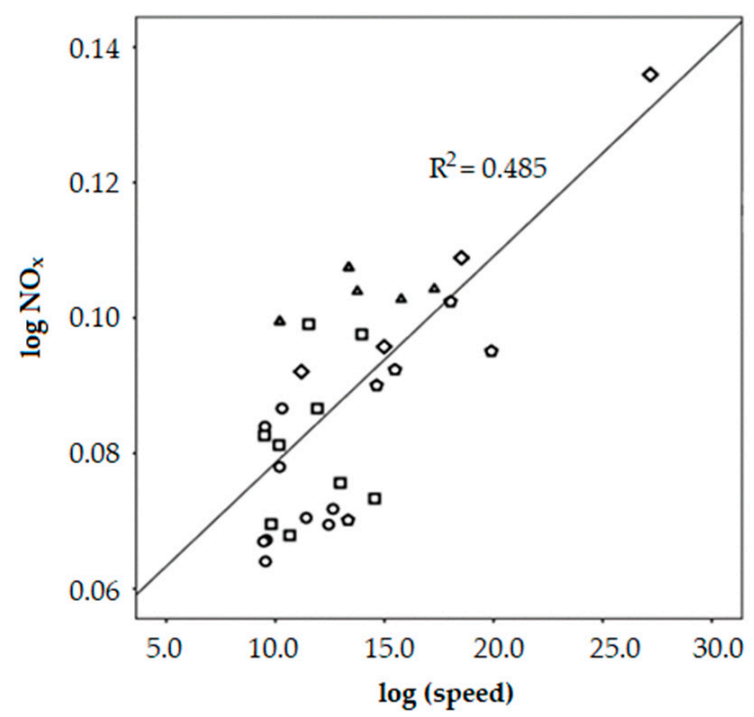

Figure 6. $\mathrm{NO}_{\mathrm{x}}$ emissions versus bus speed and the different fuels assayed: D100 (circles), B30D70 (squares), B90A10 (triangles), B95A5 (diamonds) and B47.5D47.5A2.5H2.5 (pentagons). 


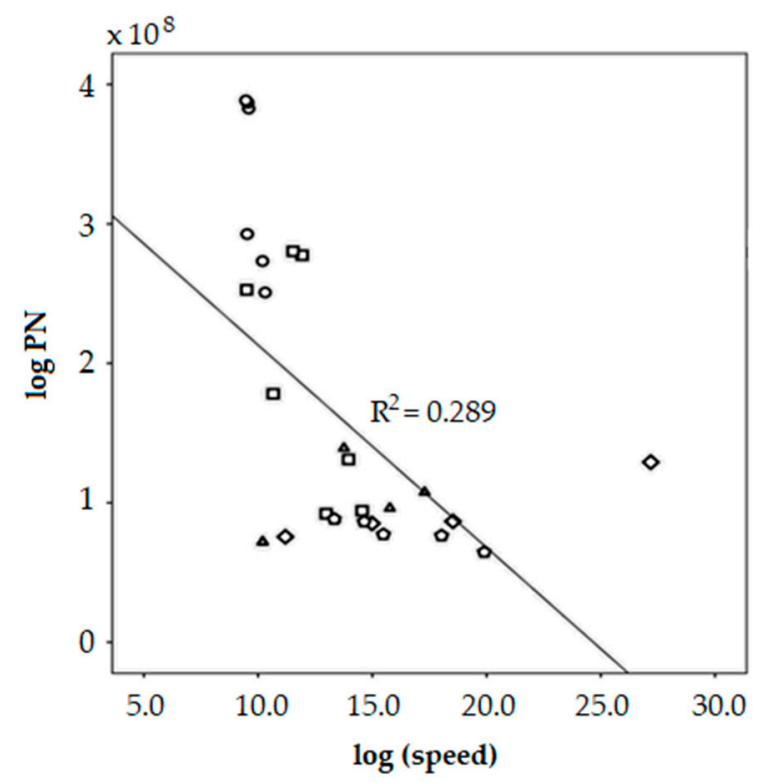

Figure 7. Total particle number (PN) emissions versus bus speed and the different fuels assayed: D100 (circles), B30D70 (squares), B90A10 (triangles), B95A5 (diamonds) and B47.5D47.5A $2.5 \mathrm{H} 2.5$ (pentagons).

\section{Conclusions}

This research demonstrates the feasibility of adding an oxygenated additive (in this case, a mixture of MAG, DAG and TAG) to second-generation biodiesel (from waste cooking oil) for its use on a EURO 3 Iveco Cityclass diesel bus. To be specific, the B47.5D47.5A2.5H2.5 blend showed better performance, in terms of THC and CO emissions, than diesel fuel. The lowest SFC was observed for this blend, which may be explained by the influence of the lower LHV of the blends compared to diesel fuel and the interaction among the thermodynamic properties of the different components of the fuel blends. Furthermore, the oxygen enrichment of the B47.5D47.5A2.5H2.5 blend, along with the lower proportion of exhaust gas recirculation (also due to the lower LHV), was responsible for a more complete combustion, which led to the decrease in SFC when using this blend. Besides, the use of heptanol as co-surfactant in the B47.5D47.5A2.5H2.5 blend favored the premix phase of the diesel combustion process and the oxygen supply, thus improving combustion efficiency. This fact is of particular interest for the use of oxygenated additives in vehicles in urban areas, where fuel consumption due to frequent starts and stops and low speeds tends to increase. Besides, the B47.5D47.5A2.5H2.5 blend provided a reduction of $\mathrm{NO}_{\mathrm{x}}$ emissions when compared to diesel, which represents another environmental advantage.

The B47.5D47.5A2.5H2.5 blend also promoted the occurrence of a smaller number of particles in accumulation mode $(>29.4 \mathrm{~nm}$ and $<191.1 \mathrm{~nm})$ and achieved the minimum average GMD $(23.32 \mathrm{~nm})$. As for the emission of particles in nucleation mode, their number was reduced by $60 \%$ in the $347.5 \mathrm{D} 47.5 \mathrm{~A} 2.5 \mathrm{H} 2.5$ blend with respect to the particles emitted by diesel fuel. The concentration of total particle number $\left(\# / \mathrm{cm}^{3}\right)$ emitted by the engine decreased when this blend was used compared with that emitted when using conventional diesel as fuel. All in all, the B47.5D47.5A2.5H2.5 blend achieved an important decrease in the pollutants studied in the exhaust gas from a EURO 3 diesel bus during its daily route through Seville city. Hence, the use of this fuel blend in buses with diesel engines without particle filters and meeting older European regulations could result in a noticeable improvement in the city air quality and, therefore, in the health of citizens of populated cities such as Seville.

Finally, the total particle number and $\mathrm{NO}_{\mathrm{x}}$ emissions were more influenced by the type of fuel than by the bus speed. 


\begin{abstract}
Author Contributions: Conceptualization, C.C.B. and P.Á.-M.; methodology, C.C.B.; software, C.C.B.; formal analysis, C.C.B., J.F.G.-M. and P.Á.-M.; investigation, A.U., D.D., J.F.G.-M., P.Á.-M. and C.C.B.; resources, C.C.B. and P.Á.-M.; data curation, J.F.G.-M.; writing-original draft preparation, C.C.B., J.F.G.-M. and P.Á.-M.; writing-review and editing, C.C.B., J.F.G.-M. and P.Á.-M.; visualization, C.C.B., J.F.G.-M. and P.Á.-M.; supervision, C.C.B.; project administration, P.Á.-M.; funding acquisition, P.Á.-M. All authors have read and agreed to the published version of the manuscript.
\end{abstract}

Funding: This research was funded by the European Union under LIFE 13 Programme, grant number LIFE13 ENV/ES/001113.

Conflicts of Interest: The authors declare no conflict of interest.

\title{
References
}

1. Monjardino, J.; Barros, N.; Ferreira, F.; Tente, H.; Fontes, T.; Pereira, P.; Manso, C. Improving air quality in Lisbon: Modelling emission abatement scenarios. IFAC-PapersOnLine 2018, 51, 61-66. [CrossRef]

2. Fameli, K.M.; Assimakopoulos, V.D. Development of a road transport emission inventory for Greece and the Greater Athens Area: Effects of important parameters. Sci. Total Environ. 2015, 505, 770-786. [CrossRef]

3. Bentita, D.; Fallole, D. Panorama et Évaluation des Différentes Filières D'autobus Urbains; Librairie Adame: Lille, France, 2018; 100p.

4. Zhang, Y.; Lou, D.; Tan, P.; Hu, Z. Particulate emissions from urban bus fueled with biodiesel blend and their reducing characteristics using particulate after-treatment system. Energy 2018, 155, 77-86. [CrossRef]

5. Chow, J.C.; Watson, J.G.; Savage, N.; Solomon, C.J.; Cheng, Y.S.; Mc Murry, P.H.; Corey, L.M.; Bruce, G.M.; Pleus, R.C.; Pleus, R.C.; et al. Nanoparticles and the environment. J. Air Waste Manag. Assoc. 2005, 55, 1411-1417. [CrossRef]

6. La Milia, D.I.; Sciaraffa, R.; Borghini, A.; Montuschi, P.; Gerosa, G.; Ricciardi, W.; Moscato, U. Impact of air pollution on respiratory diseases in urban areas: A systematic review. In Proceedings of the 11th European Public Health Conference, Ljubljana, Slovenia, 28 November-1 December 2018; pp. 317-318.

7. Dehhaghi, M.; Kazemi Shariat Panahi, H.; Aghbashlo, M.; Lam, S.S.; Tabatabaei, M. The effects of nanoadditives on the performance and emission characteristics of spark-ignition gasoline engines: A critical review with a focus on health impacts. Energy 2021, 225, 120259. [CrossRef]

8. Cornejo, A.; Barrio, I.; Campoy, M.; Lázaro, J.; Navarrete, B. Oxygenated fuel additives from glycerol valorization. Main production pathways and effects on fuel properties and engine performance: A critical review. Renew. Sustain. Energy Rev. 2017, 79, 1400-1413. [CrossRef]

9. García-Martín, J.F.; Barrios, C.C.; Alés-Álvarez, F.J.; Dominguez-Sáez, A.; Alvarez-Mateos, P. Biodiesel production from waste cooking oil in an oscillatory flow reactor. Performance as a fuel on a TDI diesel engine. Renew. Energy 2018, 125, 546-556. [CrossRef]

10. García-Martín, J.F.; Alés-Álvarez, F.J.; Torres-García, M.; Feng, C.-H.; Álvarez-Mateos, P. Production of Oxygenated Fuel Additives from Residual Glycerine Using Biocatalysts Obtained from Heavy-Metal-Contaminated Jatropha curcas L. Roots. Energies 2019, 12, 740. [CrossRef]

11. Agencia Andaluza de la Energía. Datos energéticos de Andalucía 2017; Agencia Andaluza de la Energía: Sevilla, Spain, 2017.

12. Álvarez-Mateos, P.; García-Martín, J.F.; Guerrero-Vacas, F.J.; Naranjo-Calderón, C.; Barrios, C.C.; Pérez Camino, M. del C. Valorization of a high-acidity residual oil generated in the waste cooking oils recycling industries. Grasas Aceites 2019, 70, e335. [CrossRef]

13. Rahmat, N.; Abdullah, A.Z.; Mohamed, A.R. Recent progress on innovative and potential technologies for glycerol transformation into fuel additives: A critical review. Renew. Sustain. Energy Rev. 2010, 14, 987-1000. [CrossRef]

14. Shah, P.R.; Ganesh, A. A comparative study on influence of fuel additives with edible and non-edible vegetable oil based on fuel characterization and engine characteristics of diesel engine. Appl. Therm. Eng. 2016, 102, 800-812. [CrossRef]

15. Mallesham, B.; Govinda Rao, B.; Reddy, B.M. Production of biofuel additives by esterification and acetalization of bioglycerol. C. R. Chim. 2016, 19, 1194-1202. [CrossRef]

16. García-Martín, J.F.; Alés-Álvarez, F.J.; del López-Barrera, M.C.; Martín-Domínguez, I.; Álvarez-Mateos, P. Cetane number prediction of waste cooking oil-derived biodiesel prior to transesterification reaction using near infrared spectroscopy. Fuel 2019, 240, 10-15. [CrossRef]

17. Attaphong, C.; Do, L.; Sabatini, D.A. Vegetable oil-based microemulsions using carboxylate-based extended surfactants and their potential as an alternative renewable biofuel. Fuel 2012, 94, 606-613. [CrossRef]

18. Balcan, M.; Mihăilescu, F.C.; Anghel, D.F.; Văcăreşteanu, I.C.; Aricov, L.; Vasilescu, E.L. Microemulsion systems containing diesel and colza oil as alternative fuels: Phase studies, interfacial tension and solubilization. Fuel 2014, 117, 251-258. [CrossRef]

19. Leng, L.; Yuan, X.; Zeng, G.; Chen, X.; Wang, H.; Li, H.; Fu, L.; Xiao, Z.; Jiang, L.; Lai, C. Rhamnolipid based glycerol-in-diesel microemulsion fuel: Formation and characterization. Fuel 2015, 147, 76-81. [CrossRef]

20. Zemb, T.N.; Klossek, M.; Lopian, T.; Marcus, J.; Schöettl, S.; Horinek, D.; Prevost, S.F.; Touraud, D.; Diat, O.; Marčelja, S.; et al. How to explain microemulsions formed by solvent mixtures without conventional surfactants. Proc. Natl. Acad. Sci. USA 2016, 113, 4260-4265. [CrossRef] [PubMed] 
21. Shenavaei Zare, T.; Khoshsima, A.; Zarenezhad, B. Production of New Surfactant-free Microemulsion Biofuels: Phase Behavior and Nanostructure Identification. Energy Fuels 2020, 34, 4643-4659. [CrossRef]

22. Attaphong, C.; Sabatini, D.A. Phase behaviors of vegetable oil-based microemulsion fuels: The effects of temperatures, surfactants, oils, and water in ethanol. Energy Fuels 2013, 27, 6773-6780. [CrossRef]

23. Kayali, I.; Jyothi, C.K.; Qamhieh, K.; Olsson, U. Surfactant-free alternative fuel: Phase behavior and diffusion properties. J. Colloid Interface Sci. 2016, 463, 173-179. [CrossRef] [PubMed]

24. Johnson, T.; Caldow, R.; Pöcher, A.; Mirme, A.; Kittelson, D. A new electrical mobility particle sizer spectrometer for engine exhaust particle measurements. SAE Tech. Pap. 2004, 3-5. [CrossRef]

25. Kasper, M. The number concentration of non-volatile particles-Design study for an instrument according to the PMP recommendations. SAE Tech. Pap. 2004, 1-5. [CrossRef]

26. Nabi, M.N.; Minami, M.; Ogawa, H.; Miyamoto, N. Ultra low emission and high performance diesel combustion with highly oxygenated fuel. SAE Tech. Pap. 2000, 3-5. [CrossRef]

27. Ogawa, H.; Nabi, N.; Minami, M.; Miyamoto, N.; Kim, B.S. Ultra low emissions and high performance diesel combustion with a combination of high EGR, three-way catalyst, and a highly oxygenated fuel, dimethoxy methane (DMM). SAE Tech. Pap. 2000, 106, 3-5.

28. Barrios, C.C.; Domínguez-Sáez, A.; Hormigo, D. Influence of hydrogen addition on combustion characteristics and particle number and size distribution emissions of a TDI diesel engine. Fuel 2017, 199, 162-168. [CrossRef]

29. Domínguez-Sáez, A.; Viana, M.; Barrios, C.C.; Rubio, J.R.; Amato, F.; Pujadas, M.; Querol, X. Size-resolved particle number emission patterns under real-world driving conditions using positive matrix factorization. Environ. Sci. Technol. 2012, 46, 11187-11194. [CrossRef]

30. Horiba Inc. On Board Emission Measurement System OBS-2200, Instruction Manual; Horiba Inc.: Kyoto, Japan, 2007.

31. Proyectos Medioambientales. Available online: https://www.tussam.es/es/tussam/tussam-sostenible/proyectos-medioambientales (accessed on 7 October 2020).

32. Jeevanantham, A.K.; Nanthagopal, K.; Ashok, B.; Al-Muhtaseb, A.H.; Thiyagarajan, S.; Geo, V.E.; Ong, H.C.; Samuel, K.J. Impact of addition of two ether additives with high speed diesel- Calophyllum Inophyllum biodiesel blends on NOx reduction in CI engine. Energy 2019, 185, 39-54. [CrossRef]

33. Dogan, B.; Cakmak, A.; Kadir Yesilyurt, M.; Erol, D. Investigation on 1-heptanol as an oxygenated additive with diesel fuel for compression-ignition engine applications: An approach in terms of energy, exergy, exergoeconomic, enviroeconomic, and sustainability analyses. Fuel 2020, 275, 117973. [CrossRef]

34. Barrios, C.C.; Martín, C.; Domínguez-Sáez, A.; Álvarez, P.; Pujadas, M.; Casanova, J. Effects of the addition of oxygenated fuels as additives on combustion characteristics and particle number and size distribution emissions of a TDI diesel engine. Fuel 2014, 132, 92-100. [CrossRef]

35. Gill, S.S.; Tsolakis, A.; Herreros, J.M.; York, A.P.E. Diesel emissions improvements through the use of biodiesel or oxygenated blending components. Fuel 2012, 95, 578-586. [CrossRef]

36. Barrios, C.C.; Domínguez-Sáez, A.; Martín, C.; Álvarez, P. Effects of animal fat based biodiesel on a TDI diesel engine performance, combustion characteristics and particle number and size distribution emissions. Fuel 2014, 117, 618-623. [CrossRef]

37. Lapuerta, M.; Martos, F.J.; Herreros, J.M. Effect of engine operating conditions on the size of primary particles composing diesel soot agglomerates. J. Aerosol Sci. 2007, 38, 455-466. [CrossRef]

38. Sungur, B.; Topaloglu, B.; Ozcan, H. Effects of nanoparticle additives to diesel on the combustion performance and emissions of a flame tube boiler. Energy 2016, 113, 44-51. [CrossRef] 